\title{
Perfil nutricional dos trabalhadores do manejo de eucalipto no extremo sul da Bahia
}

\author{
Nutritional profile of eucalypt management workers in the south of Bahia
}

Perfil nutricional de los trabajadores de gestión de eucalipto en el sur de Bahia

Tátila dos Santos Lima ${ }^{1 *}$, Andrea Spier ${ }^{1}$, Brenda Silveira Valles Moreira ${ }^{3}$, Marcos Lázaro da Silva Guerreiro².

\section{RESUMO}

Objetivo: Analisar o perfil nutricional dos trabalhadores do manejo de eucalipto no extremo Sul da Bahia no ano de 2018. Métodos: Estudo observacional, transversal, descritivo, com abordagem quantitativa. A amostra foi de 70 trabalhadores. A avaliação do perfil nutricional foi realizada pelo Recordatório Alimentar de 24 horas (R24H) e Questionário de Frequência Alimentar (QFA). As informações sociodemográficas foram obtidas pelo questionário estruturado. Os dados foram analisados pelo software DIETSMART® e Microsoft Exce®. Resultados: Todos os trabalhadores foram do sexo masculino e recebiam um salário mínimo. $40 \%$ tinham de 51 a 60 anos, $64,3 \%$ se autodeclararam pardos e $85,7 \%$ possuíam o $1^{\circ}$ grau incompleto. Dentre as morbidades autorreferidas, a dor crônica esteve em $42,9 \%$. O consumo alimentar foi representado pela alta ingestão de carboidratos $(68,4 \%)$. A média do balanço energético mostrou-se negativada. Quanto ao diagnóstico nutricional, 57,1\% estavam em estado de desnutrição de acordo com a circunferência muscular do braço, e com relação ao IMC, 47,3\% estavam acima do peso. Conclusão: Pôde-se perceber que existe um excesso de peso associado à sarcopenia nesses trabalhadores, trazendo preocupações referentes ao perfil nutricional, estado de saúde e qualidade de vida, sendo necessário novos olhares para a nutrição dos trabalhadores silvicultores.

Palavras-chave: Estado nutricional, Eucalipto, Saúde do trabalhador.

\begin{abstract}
Objective: Analyze the nutritional profile of the extreme South of Bahia workers of eucalyptus in the year of 2018. Methods: An observational study, transversal, descriptive, with a quantities approach. The sample was from 70 workers. The nutritional profile evaluation was realized by Food Recall of 24 hours (R24H) and Alimentary Frequency Quiz (QFA). The sociodemographic information was obtained by a structured quiz. The datas were analyzed by DIETSMART® software and Microsoft Exce®. Results: All the workers were male and earned minimum salary. $40 \%$ had between 51 and 60 years, 64,3\% declared brown and $85,7 \%$ had elementary school incomplete. Among the self-reported morbidities, the chronicle pain was in $42,9 \%$. The alimentary consume was represented by the higher ingestion of carbohydrates (68,4\%). The average of energetic balance was negative. According to nutritional diagnostic, $57,1 \%$ were in a state of malnutrition according the arm muscular circumference, regarding the ICM, 47,3\% were above their weight. Conclusion: Was observed that exist a relation between the overweight and sarcopenia in this workers, resulting in concerns regarding this nutritional profile, health state and life quality, being necessary news approach to this foresters workers nutrition.
\end{abstract}

Keywords: Nutritional status, Eucalyptus, Occupational health.

\footnotetext{
${ }^{1}$ Faculdade de Tecnologia e Ciências (FTC), Itabuna - BA. *E-mal: tatilanutri@yahoo.com.br

2 Faculdade de Tecnologia e Ciências (FTC), Salvador - BA

3 Universidade Federal de Viçosa (UFV), Viçosa - MG
} 


\section{RESUMEN}

Objetivo: Analizar el perfil nutricional de los trabajadores del eucalipto de la región en extremo Sur de Bahía en el año de 2018. Métodos: estudios de observación, transversal, descriptivo, con una abordaje cuantitativo. La amuestra fuera de 70 trabajadores. La avaluación del perfil nutricional fuera de pelo Retiro de Alimentos de 24 horas (R24H) y Cuestionario de Frecuencia Alimentaria (QFA). Las informaciones sociodemográficas obtendrán pelo pelo cuestionario estructurado. Los dados fueron analizados con el software DIETSMART® y Microsoft Excel $\AA^{\circledR}$. Resultados: Todos los trabajadores tenían hombres y tenían como sueldo un salario mínimo. $40 \%$ de 51 hasta 60 años, $64,3 \%$ se declararon marrones y $85,7 \%$ de la enseñanza fundamental incompleta. Entre las morbilidades auto informadas, la dolor crónico estuve entre $42.9 \%$. El consumo alimentario fue considerado pela grande ingestión de carbohidratos $(68,4 \%)$. La media del balance energético fuera negativa. Respecto al diagnóstico nutricional, 57,1\% estaban en estado de desnutrición en acordó con la circunferencia muscular de su brazo, y en relación al IMC, 47,3\%, estaban sobre peso. Conclusión: Puedes concluir que existe una relación entre el peso cons la sarcopenia en los trabajadores, lo que trae preocupación en la relación al perfil nutricional, su salud y calidad de vida, siendo necesario una nueva manera de mirar para la nutrición de los trabajadores silvicultores.

Palabras clave: Estado nutricional, Eucalyptus, Salud laboral.

\section{INTRODUÇÃO}

A alimentação é uma necessidade básica na vida dos indivíduos, influenciando diretamente na execução das atividades humanas e na qualidade de vida, por estar relacionada à manutenção, prevenção e recuperação da saúde. Entretanto, para atingir esses objetivos é necessário que seja saudável, completa, variada, agradável ao paladar e segura (ZANDONADI RP, et al., 2007). Nesse sentido, as políticas públicas voltadas para o âmbito da seguridade alimentar, incentivam a população a criar hábitos saudáveis no intuito de intervir na formação de um perfil nutricional pautado no bem-estar, envelhecimento saudável e prevenção de doenças (BRASIL, 2014).

A investigação do perfil nutricional tem como objetivo conhecer a ingestão energética e de nutrientes, carências nutricionais, presença de desnutrição, excesso de peso, bem como os fatores de risco para doenças crônicas não transmissíveis e doenças (DCNT) e cardiovasculares (BRASIL, 2014). Havendo uma deficiência entre o consumo de nutrientes em relação às necessidades ou àquelas resultantes do excesso e/ou do desequilíbrio do consumo alimentar em relação ao gasto energético do corpo, recebe a classificação de carência nutricional, podendo ser representado por distúrbios nutricionais como a obesidade e a desnutrição (VASCONCELOS FAG, 2007).

No panorama brasileiro, a adesão de políticas públicas para o controle da desnutrição e pobreza se intensificou a partir de 1995 com a criação do Programa de Erradicação do Trabalho Infantil (PETI). Já em 2000, foram criados os Programas Bolsa Escola, Bolsa Alimentação, Cartão Alimentação e Vale Gás. Posteriormente, em 2003, e prevalecendo até os dias atuais, todos esses programas foram unificados no Programa Bolsa Família, que é considerado pela Organização das Nações Unidas (ONU) o maior programa de transferência de renda já realizado no mundo e a maior estratégia de combate à fome (DE MEDEIROS BT, et al., 2017).

Entretanto, com a globalização e a influência midiática junto com a menor taxação de impostos sobre alimentos como açúcar, doces industrializados e alimentos com alto teor de gordura saturadas e sal, resultaram em mudanças no perfil nutricional e na saúde. Logo, no Brasil impera uma transição nutricional baseada na má-alimentação, e essa transição se dá pela diminuição da fome e desnutrição, aonde se apresentava altas taxas na década de 1970, passando a ser, em 2008, um país com metade da população adulta com sobrepeso e obesidade, portando em sua maioria, com doenças crônicas não transmissíveis e cardiovasculares (SOARES LR, et al., 2014).

No tocante ao setor florestal, existe uma prevalência do trabalho braçal no manejo do eucalipto, incluindo principalmente as atividades que envolvem o plantio e coveamento, nesse cenário, os trabalhadores que 
estão expostos às atividades manuais têm um gasto energético elevado, necessitando assim, de um maior aporte nutricional (NASCIMENTO KAO, et al., 2018).

Quando este não ocorre, ou seja, mediante o trabalho manual excessivo associado com a baixa ingestão de alimentos com potencial anti-inflamatório, pode resultar em aumento excessivo de radicais livres. As principais consequências desse desarranjo estão relacionadas com o surgimento da inflamação crônica e suas consequências, podendo ocasionar DCNT, doenças cardiovasculares, câncer, dores crônicas, prejuízos atléticos entre outras (CATTELAN MDP, 2017).

A inflamação crônica é o gatilho para as principais doenças da atualidade. As causas para inflamação crônica são diversas, incluindo um estilo de vida inadequado, como ingestão de alimentos inflamatórios e excesso de exercício físico. Alguns elementos alimentares já foram suficientemente estudados para serem caracterizados como pró ou anti-inflamatórios, existindo assim estratégias alimentares que modulam genes inflamatórios, fazendo o seu silenciamento e também alimentos que fazem estímulos de receptores inflamatórios propiciando o aumento das citocinas inflamatórias (BRUNO L e CASTRO R, 2018).

Dentre os componentes alimentares considerados anti-inflamatórios estão: grãos integrais, fibras, frutas e vegetais, as oleaginosas, peixes, as vitaminas com grande potencial antioxidante como a $\mathrm{C}$ e $\mathrm{E}$; os considerados pró-inflamatórios estão: produtos de glicação avançada (AGEs - ácidos graxos essenciais), ácidos graxos saturados, ácidos graxos trans, ômega-6 e carboidratos refinados (CALDER PC, et al., 2011).

O desequilíbrio entre a produção de radicais livres, espécies reativas de oxigênio formados durante o metabolismo celular, e as defesas antioxidantes resulta em estresse oxidativo, podendo ter efeitos deletérios sobre algumas moléculas, incluindo proteínas, lipídios, ácido ribonucleico (RNA) e ácido desoxirribonucleico (DNA) (LOBO et al., 2010).

Nosso organismo possui mecanismos de defesa antioxidante enzimático endógeno, que destroem esses radicais livres, como, por exemplo, a superóxido dismutases, catalases e glutationa peroxidase, entretanto, para uma boa funcionalidade precisam de micronutrientes antioxidantes (encontrado em alimentos), como vitamina $A, D, E, K, C, B 2, B 6, B 9, B 12$, zinco, magnésio, e alguns fitoquímicos que agem como cofatores para essas enzimas antioxidantes ou como parte da estrutura de proteínas envolvidas na síntese, reparo e prevenção do dano oxidativo ao DNA (CASTRO R e BRUNO L, 2017).

O número de trabalhadores florestais na Bahia tem crescido, pois o estado possui uma ativa participação nacional no âmbito florestal, e no ano de 2014, era o quinto produtor de florestas no país, com $94 \%$ dos plantios de eucalipto (ABAF, 2015).

Com essa expansão do setor florestal na Bahia, em 2016, foi gerado 228,7 mil empregos (diretos, indiretos e efeito-renda), incorporando as diversas atividades que compõem o setor florestal desde o pré-plantio (preparo de mudas e terreno), efetivo plantio e colheita florestal até o efetivo processamento industrial dos diferentes produtos de madeira (ABAF, 2018).

Apesar dessa franca expansão do crescimento da produção e modernização tecnológica, não houve melhorias nas condições de vida e de trabalho no meio rural, pelo contrário, mais uma vez fica evidenciada a histórica exploração da força de trabalho com o consequente aumento dos fatores de risco referentes à saúde dos trabalhadores (MENEGAT RP e FONTANA RT, 2010). Em contrapartida, no Brasil há uma grande preocupação em promover um modelo de produção sustentável.

Tal modelo tem enfoque na garantia da saúde, bem-estar, prevenção de acidentes e garantia dos direitos dos trabalhadores devido ao alto índice de doenças relacionadas à exposição a fatores de riscos laborais (ruídos, agentes químicos, biológicos, isolamento geográfico, calor, umidade, dentre outros), doenças tropicais (malária, dengue, hanseníase, leishmaniose, doença de chagas e febre amarela) em decorrência do local de trabalho, e distúrbios nutricionais como sobrepeso, obesidade e desnutrição (OIT, 2009).

Diante do exposto, identificar os riscos nutricionais que esses trabalhadores envolvidos no setor florestal estão submetidos, é uma estratégia importante para traçar medidas que visem a promoção, proteção e reabilitação da saúde desse público que utiliza de grande esforço físico laboral. A partir disso, trazer benefícios 
à saúde individual, familiar e coletiva. Nessa perspectiva, objetivou-se com esse estudo avaliar o perfil nutricional de trabalhadores envolvidos no manejo do eucalipto em uma empresa localizada no extremo Sul da Bahia no ano de 2018.

\section{MÉTODOS}

Trata-se de um estudo observacional, transversal, descritivo e de campo, com abordagem quantitativa. $O$ estudo foi realizado em três fazendas produtoras de eucalipto situadas no extremo Sul da Bahia, por meio da assistência prestada por uma empresa certificada, de cunho privado. $O$ estudo foi desenvolvido sob permissiva da empresa supracitada, sem vínculos de patrocínio ou fins lucrativos.

A população deste estudo foram todos os trabalhadores silvicultores de eucalipto que exercem atividades manuais na referida empresa. Os critérios de inclusão foram: trabalhadores que exercessem atividades exclusivas no campo, com trabalho exclusivamente manual, vinculados legalmente a empresa e que aceitassem participar do estudo por meio da assinatura do Termo de Consentimento Livre e Esclarecido (TCLE).

Os critérios de não-inclusão foram aqueles que estavam afastados temporariamente ou definitivamente por acidentes, doenças ocupacionais, atestados médicos, período férias e aposentadoria. A coleta de dados ocorreu por meio da aplicação de um questionário estruturado, composto por dados de identificação do trabalhador, dados sociodemográficos e ocupacionais, dados básicos de saúde ocupacional, dados básicos de saúde integral, hábitos de vida, inquéritos alimentares e análise dos inquéritos alimentares, medidas antropométricas, composição corporal, parâmetros bioquímicos.

A avaliação do perfil nutricional desses trabalhadores foi realizada por meio de questionários de Inquérito Alimentar através do método Recordatório Alimentar de 24 horas (R24H) e Questionário de Frequência Alimentar (QFA) (FISBERG RM, et al., 2005).

As medidas de peso e altura foram aferidas por uma Balança Digital com medidor de altura digital da marca WISO, modelo W721 com capacidade para $180 \mathrm{~kg}$ e com sensor de alta precisão. As medidas antropométricas foram aferidas por uma trena antropométrica inelástica, inextensível, marca SANNY, com 2 metros de comprimento e aplicando o calibrador do adipômetro clínico Sanny (resolução em milímetros (mm), faixa de medição de 0 a $55 \mathrm{~mm}$, tolerância de $1 \mathrm{~mm}$ em $55 \mathrm{~mm}$ ) no ângulo reto. Os dados obtidos foram quantificados e analisados com o auxílio do software DIETSMART® e Microsoft Excel®.

A pesquisa foi desenvolvida de acordo com os critérios éticos da Resolução 466/2012 do Conselho Nacional de Saúde. Foi encaminhado ao Comitê de Ética em Pesquisa da Faculdade de Tecnologia e Ciências para apreciação e aprovado por meio do parecer número: CAAE 2.513.272.

\section{RESULTADOS E DISCUSSÃO}

O universo da população estudada compreendeu 70 trabalhadores silvicultores de eucalipto, todos do sexo masculino e no desempenho de suas atividades laborais, todos apresentaram exposição a risco físico, biológico e químico.

Com relação ao diagnóstico nutricional (Tabela 1), a avaliação segundo o Índice de Massa Corporal (IMC) entre os trabalhadores da silvicultura de eucalipto mostrou que a maioria dos indivíduos está adequada (51.4\%) ou acima do peso (47.3\%).

No entanto, quando esta população foi avaliada através dos parâmetros da Circunferência do Braço (CB) e Circunferência Muscular do Braço (CMB), que avaliam massa muscular e a Prega Cutânea do Tríceps (PCT) que avalia o tecido adiposo, esses parâmetros indicaram déficits nesses compartimentos.

Com isso, pôde-se notar que a desnutrição esteve presente em $52,9 \%$ dos trabalhadores, quando analisados os dados referentes à medida da CB. Na medida da PCT, 45,7\% tiveram o diagnóstico de desnutrição e na $\mathrm{CMB}$, a desnutrição se apresentou em 57,1\%. As alterações que ocorrem na composição corporal, como a diminuição de massa magra, trazem prejuízo na força muscular (MARTIN FG, et al., 2012). 
Tabela 1 - Dados antropométricos de trabalhadores florestais em atividade manual de uma empresa prestadora de serviço, extremo sul da Bahia/2018.

\begin{tabular}{lcc}
\hline Variáveis & Trabalhador (n) & Trabalhador (\%) \\
\hline Índice de Massa Corporal (IMC) & 1 & 1,4 \\
\hline Magreza & 36 & 51,4 \\
Eutrofia & 27 & 38,6 \\
Sobrepeso & 6 & 8,6 \\
Obesidade & & \\
\hline Circunferência do Braço (CB) & 32 & 45,7 \\
\hline Eutrofia & 37 & 52,9 \\
Desnutrição & 1 & 1,4 \\
Sobrepeso & 0 & 0 \\
Obesidade & & \\
\hline Circunferência Muscular do Braço (CMB) & 30 & 42,9 \\
\hline Eutrofia & 40 & 57,1 \\
Desnutrição & 0 & 0 \\
Sobrepeso & 0 & 0 \\
Obesidade & & 18,6 \\
\hline Prega Cutânea Tricipital (PCT) & 13 & 45,7 \\
\hline Eutrofia & 32 & 7,1 \\
Desnutrição & 5 & 28,6 \\
Sobrepeso & 20 & \\
Obesidade & &
\end{tabular}

Fonte: Lima TS, et al., (2020).

Os achados referentes ao IMC se assemelham ao estudo de delineamento transversal, realizado com 699 homens adultos, trabalhadores de uma empresa de reflorestamento. Dos trabalhadores investigados, apenas $2,15 \%$ foram classificados com desnutrição, $74,54 \%$ classificados com eutrofia e $23,31 \%$ dos trabalhadores foram classificados com excesso de peso (SOUZA TT, 2014). Entretanto, o estudo supracitado exclui as medidas com maior precisão do perfil de massa magra e gordura corporal, como a CB, PCT e CMB, as quais resultaram neste estudo a prevalência de desnutrição entre os trabalhadores.

Tal relação pode ser justificada pelo balanço energético negativo, uma vez que o consumo em energia é inferior ao gasto (Gráfico 1). Cortez ACL et al. (2015) reforçam ao falar que o IMC é o indicador antropométrico mais utilizado para avaliar o estado nutricional. No entanto, este indicador isolado não traz informações sobre a composição corporal, sendo necessária a combinação com outros indicadores como a circunferência muscular do braço.

Glaner MF (2005) colabora ao falar que, ao avaliar em seu estudo o IMC como indicativo da gordura corporal comparado às dobras cutâneas, concluiu que a adoção deste de forma isolada pode resultar em um diagnóstico incorreto (CUPARRI L, 2005).

A qualidade alimentar está relacionada tanto ao consumo de macronutrientes (alimentos energéticos), quanto ao consumo de micronutrientes (alimentos não energéticos). Os micronutrientes compreendem as vitaminas e minerais, encontradas principalmente em frutas, legumes e verduras. São indispensáveis para o ideal funcionamento do organismo por atuarem no crescimento e desenvolvimento, além de tereminfluências sobre funções metabólicas (DONATTO FF, 2018).

No tocante ao consumo médio de macronutrientes, essa pesquisa mostrou um consumo além do recomendado no grupo dos carboidratos $(68,37 \%)$, ao passo que as gorduras monoinstaturadas e poliinsaturadas, consideradas anti-inflamatórias, tiveram uma ingestão abaixo do recomendado. Já o consumo de proteínas, lipídios e gorduras saturadas tiveram seu consumo dentro da faixa recomendada pelas DRl's (Tabela 2). 
Tabela 2 - Consumo médio de macronutrientes dos trabalhadores florestais em atividade manual no ano de 2018 por meio do recordatório de 24 horas versus recomendações da Dietary Reference Intakes (DRIs), 2011.

\begin{tabular}{ccc}
\hline Nutrientes & Recomendações DRI's & Consumo médio \\
\hline Carboidrato & 45 a $65 \%$ & $68,37 \%$ \\
Proteína & 10 a 35\% & $14,67 \%$ \\
Lipídios & 20 a 35\% & $16,96 \%$ \\
Gordura saturada & $\leq 10 \%{ }^{1}, \leq 7 \%^{2}$ & $6,52 \%$ \\
Gordura monoinsaturada & $15 \%$ & $6,91 \%$ \\
Ácidos graxos poli-insaturados & 5 a $10 \%$ & $3,9 \%$ \\
\hline
\end{tabular}

Legenda: ${ }^{1}$ Sem comorbidade. ${ }^{2}$ Com comorbidade. Fonte: Lima TS, et al., (2020).

Shelton RC e Miller AH (2010) colaboram ao falar que o excesso de carboidratos de alto índice glicêmico, como os cereais refinados (pão e massas em geral), são grandes geradores de espécies reativas de oxigênio como o peroxidohidrogênio $\left(\mathrm{H}_{2} \mathrm{O}_{2}\right)$, fazendo estímulo de fatores transcricionais chaves que aumentam expressão de proteínas inflamatórias. Contribuindo para o surgimento de DCNT, inflamações articulares, além de estar relacionado com fadiga crônica.

Com relação à ingestão de micronutrientes antioxidantes, foi evidenciada de uma forma geral, a baixa ingestão, com exceção do zinco (13,44 mg), que teve seu consumo médio diário acima do recomendado pelas DRIS (2011), que são de 11 mg (Tabela 3).

Tabela 3 - Consumo médio de micronutrientes antioxidantes dos trabalhadores florestais em atividade manual no ano de 2018 por meio do recordatório de 24 horas versus recomendações da Dietary Reference Intakes (DRIs) 2011.

\begin{tabular}{lcc}
\hline Nutrientes & Recomendações DRIs & Consumo médio \\
\hline Vitamina A & $900 \mathrm{mcg}$ & 184,14 \\
Vitamina E & $15 \mathrm{mg}$ & 2,49 \\
Vitamina C & $90 \mathrm{mg}$ & 26,31 \\
B6 (Piridoxina) & $1.3 \mathrm{mg}^{1} ; 1.7^{2} \mathrm{mg}$ & 0.45 \\
B9 (Folato) & $400 \mathrm{mcg}$ & 39.36 \\
B12 & $2,4 \mathrm{mcg}$ & 1.73 \\
Magnésio & $400 \mathrm{mg}^{3} ; 420 \mathrm{mg}^{4}$ & 330,2 \\
Selênio & $55 \mathrm{mcg}$ & 18.60 \\
Zinco & $11 \mathrm{mg}$ & 13.44 \\
\hline
\end{tabular}

Legenda: ${ }^{1}$ Faixa etária de 19 a 50 anos. ${ }^{2}$ Faixa etária de 51 a 70 anos. ${ }^{3}$ Faixa etária de 19 a 30 anos. ${ }^{4}$ Faixa etária superior a 30 anos. Fonte: Lima TS, et al., (2020).

Marcon F et al. (2011), mostraram em seu estudo a relação existente entre a dieta e o telômero (parte do cromossomo que compreende a replicação e longevidade celular). Eles comprovaram que uma baixa ingestão de micronutrientes com potencial antioxidante, associada ao consumo de alimentos com potencial inflamatório, como o leite e seus derivados e carne vermelha acima de $100 \mathrm{~g} / \mathrm{dia}$, estão relacionados com o encurtamento do telômero. Esse encurtamento, por sua vez, está relacionado com envelhecimento precoce, aumento do estresse oxidativo e aumento da resposta inflamatória. Sendo assim, mais uma vez, que os trabalhadores pesquisados apresentam uma dieta que favorece o estresse oxidativo e a inflamação, o que pode estar impactando negativamente em seu estado de saúde. A alimentação dos trabalhadores foi marcada predominantemente pelo alto consumo de alimentos inflamatórios, onde os cereais refinados e carnes com gordura foram consumidos com frequência igual ou superior a 6 dias da semana por todos os trabalhadores. Ademais, percebeu-se a alta ingestão de açúcares, onde 98,5\% deles consumiam de 6 a 7 dias, e de embutidos, em que $92,8 \%$ consumiam de 3 a 5 dias na semana (Tabela 4). 
Tabela 4 - Frequência do consumo semanal de alimentos inflamatórios pelos trabalhadores florestais em atividade manual no ano de 2018 de acordo com o Questionário de Frequência Alimentar (QFA).

\begin{tabular}{cccc}
\hline & Consumo semanal & & \\
\hline Alimentos & $\begin{array}{c}\leq 2 \text { dias } \\
\%(\mathrm{n})\end{array}$ & $\begin{array}{c}\geq 3 \mathrm{a} \leq 5 \text { dias } \\
\%(\mathrm{n})\end{array}$ & $\begin{array}{c}\geq \text { a } 6 \text { adias } \\
\%(\mathrm{n})\end{array}$ \\
\hline Cereais refinados* $^{*}$ & 0 & 0 & $100(70)$ \\
Carnes com gordura & 0 & 0 & $100(70)$ \\
Leite integral & $30(21)$ & $12,8(9)$ & $57,14(40)$ \\
Lanches Fritos & $100(70)$ & 0 & 0 \\
Embutidos & 0 & $92,8(65)$ & $7,1(5)$ \\
Gordura/sódio**** $_{\text {Açúcares }}^{* * * *}$ & $50(35)$ & $21,4(15)$ & $28,5(20)$ \\
Bebida alcoólica & $1,4(1)$ & 0 & $98,5(69)$ \\
\hline
\end{tabular}

Legenda: *Pães, massas em geral, macarrão, biscoito e arroz branco. ${ }^{* *}$ Batata frita, nuggets, batata chips, salgado frito (coxinha, quibe, pastel). ${ }^{* * *}$ Salsicha, mortadela, presunto e linguiça. ${ }^{* * *}$ Bolachas e biscoitos salgados. ${ }^{* * * \star *}$ Refrigerante, suco artificial, biscoito recheado, balas, chocolates, açúcar branco. Fonte: Lima TS, et al., (2020).

Em contrapartida, percebeu-se de uma forma geral, a baixa ingestão de alimentos anti-inflamatórios (os quais são protetores do organismo contra a inflamação), excetuando-se o feijão, que foi consumido por todos por mais de 5 dias durante a semana. Os alimentos ricos em fitoquímicos, como salada, legumes, frutas e chás tiveram a menor frequência de ingestão (BATTINO M, et al., 2020). O grupo dos alimentos ricos em proteínas com propriedades anti-inflamatórias, como peixes e ovos, também foram poucos consumidos (Tabela 5).

Tabela 5 - Frequência do consumo de alimentos anti-inflamatórios de acordo com o Questionário de Frequência Alimentar (QFA) aplicado aos trabalhadores florestais em atividade manual no ano de 2018.

\begin{tabular}{|c|c|c|c|}
\hline \multicolumn{4}{|c|}{ Consumo semanal } \\
\hline & $\leq 2$ dias & $\geq 3$ a $\leq 5$ dias & $\geq$ a 6 dias \\
\hline Alimentos & $\%(n)$ & $\%(n)$ & $\%(n)$ \\
\hline Salada* $^{*}$ & $39(55,7)$ & $20(28,5)$ & $11(15,7)$ \\
\hline Legumes ** & $51(72,8)$ & $12(17,1)$ & $7(10)$ \\
\hline Cereais Integrais ${ }^{\star \star *}$ & $65(92,8)$ & $3(4,2)$ & $2(2,8)$ \\
\hline Frutas & $39(55,7)$ & $19(27,14)$ & $12(17,14)$ \\
\hline Feijão & 0 & 0 & $70(100)$ \\
\hline Peixes & $69(98,5)$ & $1(1,4)$ & 0 \\
\hline Ovos & $62(88,5)$ & $7(10)$ & $1(1,42)$ \\
\hline Chá & $38(54,2)$ & $22(31,4)$ & $10(14,2)$ \\
\hline
\end{tabular}

Legenda: * Salada crua (alface, couve, rúcula, espinafre, tomate, pepino, repolho). ** Cenoura, abóbora, chuchu, brócolis, abobrinha e quiabo. ${ }^{* *}$ Raízes e tubérculos. Fonte: Lima TS, et al. (2020).

Os alimentos com propriedades anti-inflamatórias, em sua grande maioria, possuem fitoquímicos. Os fitoquímicos são definidos como compostos biativos/antioxidantes encontrados em plantas, frutas e outros alimentos vegetais, sendo responsáveis pela coloração e outras propriedades sensoriais desses alimentos. O seu consumo está diretamente relacionado com a diminuição do risco de desenvolvimento das doenças crônicas, e até mesmo com o tratamento dessas (AHMAD T, et al., 2019). 
Com relação ao gasto energético elevado (Gráfico 1), sabe-se que contribui para o aumento do estresse oxidativo, induzido pelo excesso de radicais livres, que quando não controlado pelos fitoquímicos (compostos antioxidantes) encontrados em alimentos/plantas com potencial anti-inflamatório, reflete em inúmeros eventos ao organismo, entre eles, doenças neurodegenerativas, crônicas, dores articulares e prejuízos atlético (AJIT D, et al., 2016).

Gráfico 1 - Análise do Valor Energético Total (VET) versus Gasto Energético Total (GET) dos trabalhadores florestais em atividade manual no ano de 2018.

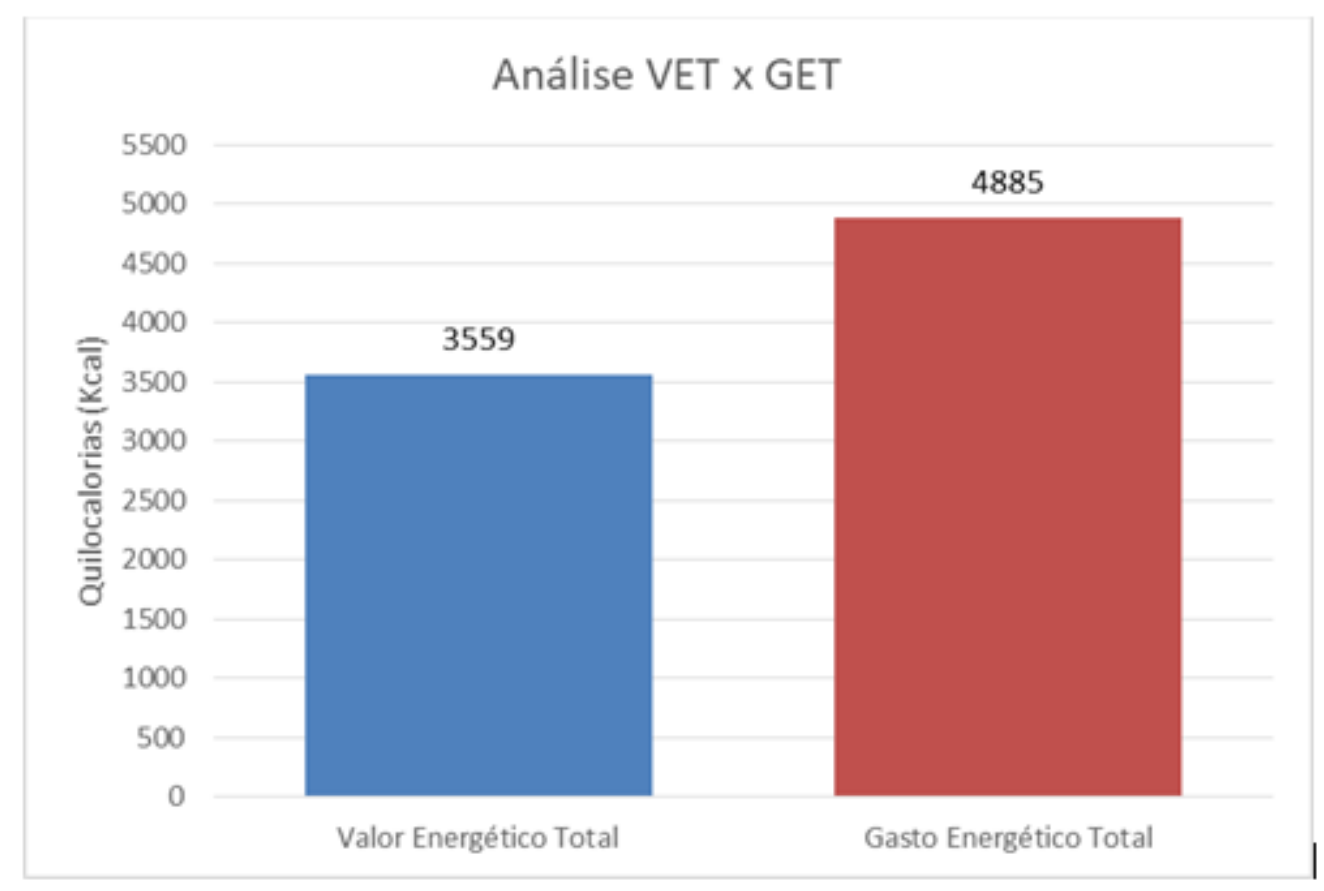

Fonte: Lima TS, et al., (2020).

Ultimamente, tem-se dado uma maior atenção para o campo da química dos radicais livres. Os radicais livres são espécies reativas de oxigênio e de nitrogênio, gerados pelo nosso organismo por vários sistemas endógenos, estados patológicos, estresse, excesso de atividade física, ingestão de substâncias presentes em alimentos (aditivos químicos, hormônios, entre outros) (BRESSAN J, et al., 2009). Para uma função fisiológica adequada, é preciso que haja um equilíbrio entre radicais livres e antioxidantes. Caso os radicais livres excedam a capacidade do corpo de regulá-los, ocorre uma condição conhecida como estresse oxidativo. Portanto, esse desequilíbrio mediado pelo estresse oxidativo, altera adversamente proteínas funcionais (proteólise), DNA e desencadeiam várias doenças humanas (LOBO V, et al., 2010). Dessa forma, vê-se os trabalhadores da pesquisa como possíveis alvos dessas doenças.

Burhans WC e Heintz NH (2009) enfatizam que uma atividade que exija esforço físico, faz estímulo de lesão muscular, promove ganho de massa magra e consequentemente o aumento da força. Entretanto, se não houver equilíbrio entre produção de radicais livres e defesa antioxidante, a lesão muscular pode evoluir para uma lesão articular, por indução no aumento de marcadores inflamatórios. Como os trabalhadores pesquisados desempenham suas atividades sob condições climáticas adversas e sob grande esforço físico, tal equilíbrio pode estar prejudicado. É nesse contexto que uma alimentação equilibrada em macro e micronutrientes poderia ser uma das estratégias para estar reduzindo a quantidade de marcadores inflamatórios no organismo, e, consequentemente, prevenindo lesões lesões (SCHEURIG AC, et al., 2008).

No tocante às morbidades autorreferidas pelos trabalhadores florestais, as DCNT não apresentaram grandes incidências: Hipertensão Arterial Sistêmica (15,7\%), Diabetes Mellitus (1,42\%) e Dor crônica (42,9\%). Tal realidade pode estar associada ao baixo grau de instrução dos trabalhadores, ao baixo acesso aos serviços de saúde e até mesmo à omissão para evitar prejuízos e exposições no trabalho. 
Apesar da hipertensão não ter sido citada de forma expressiva na pesquisa, essa informação é autorreferida, pois a faixa etária de maior acometimento é a população mais velha e atinge mais homens que mulheres (OMS, 2010). Além disso, a hipertensão é doença silenciosa e pode atingir as pessoas que não mantém um controle dos níveis pressóricos e com comportamentos de estilo de vida inadequados (OMS, 2010).

Estudo realizado com pessoas acima de 60 anos na cidade de Juiz de Fora - Minas Gerais, com objetivo de avaliar o gasto mensal com medicações, concluiu-se que a hipertensão arterial sistêmica é a doença responsável por maior parte dos gastos com medicamentos e esse gasto é proporcional ao envelhecimento, principalmente entre usuários do SUS. (DE OLIVEIRA TF, et al., 2019). Sendo assim, pode ser que acometimentos na pesquisa sejam maiores do que os relatados, o que merece um acompanhamento mais detalhado para inferências mais seguras acerca desses dados. Mais uma vez, a baixa expressividade nesses dados pode estar relacionada ao baixo acesso aos serviços de saúde e ao reduzido grau de escolaridade dos trabalhadores.

A dor crônica, presente nos resultados da pesquisa, muito embora não correspondam à maioria da população em estudo, é um achado preocupante e torna-se significativo, a partir do momento em que esse acometimento pode interferir diretamente na produtividade e na qualidade de vida. É definida como um quadro de inflamação representadas pelos sinais e sintomas de calor, dor, rubor, edema e perda da função, tendo relação direta com o estilo de vida inadequado, ingestão abusiva (acima das recomendações das necessidades diárias) de carboidratos refinados e excesso de esforço físico (BRUNO L e CASTRO R, 2018). Além disso, a prática de hábitos alimentares saudáveis, com redução da ingestão de gordura (trans e as saturadas), aumento do consumo de frutas, hortaliças e cereais integrais parecem estar associados com a melhora do estado inflamatório subclínico (BRUNO L e CASTRO R, 2018).

\section{CONCLUSÃO}

Foi possível perceber as diversas condições adversas em que os trabalhadores silvicultores estão expostos durante o período de trabalho físico braçal. Evidenciou-se a necessidade de melhorias individuais e coletivas nas práticas relativas à atividade física e de padrão alimentar, seja esse dentro fora do ambiente de trabalho. Tais adequações mostram-se necessárias uma vez que, seguindo os novos estudos desenvolvidos na área, bem como aqueles que retratam o perfil de adoecimento dessa população, os hábitos encontrados nessa população podem contribuir negativamente com o surgimento das DCNT, fadiga e da dor crônica naqueles em que ainda não as apresentam. As limitações do estudo podem estar relacionadas à pesquisa ter sido desenvolvida em apenas uma empresa, sugerindo-se estudos de maior abrangência na temática.

\section{REFERÊNCIAS}

1. ABAF. Associação Baiana das Empresas de Base Florestal. Bahia florestal relatório ABAF 2015.

2. AJIT D, et al. Phytochemicals and botanical extracts regulate NF-KB and Nrf2/ARE reporter activities in DI TNC1 astrocytes. Neurochemistry international, 2016; 97: 49-56.

3. Associação Baiana das Empresas de Base Florestal - ABAF. Relatório de ações ABAF e do setor florestal em 2018. Salvador-BA, 2018. 03 p.

4. BATTINO M, et al. The roles of strawberry and honey phytochemicals on human health: a possible clue on the molecular mechanisms involved in the prevention of oxidative stress and inflammation. Phytomedicine, 2020, 153170.

5. BRASIL. Ministério da Saúde. Guia alimentar para a população brasileira. 2.ed. Brasília, 2014. 156 p.

6. BRESSAN J, et al. Impacto hormonal e inflamatório de diferentes composições dietéticas: ênfase em padrões alimentares e fatores dietéticos específicos. Arquivos Brasileiros de Endocrinologia \& Metabologia, 2009, 53.5: 572581.

7. BRUNO L e CASTRO R. Reprogramando seus genes pela alimentação. 1 ed. São Paulo: PoloBooks, 2018

8. BURHANS WC e HEINTZ NH. The cell cycle is a redox cycle: linking phase-specific targets to cell fate. Free Radical Biology and Medicine, 2009; 47(9): 1282-1293.

9. CALDER PC, et al.. Dietary factors and low-grade inflammation in relation to overweight and obesity. British Journal of Nutrition, v. 106, n. 3, p. S1-S78. 2011.

10. CASTRO R e BRUNO L. Alvos genéticos e epigenéticos: estratégias nutricionais eficientes. 1.ed. São Paulo: PoloBooks, 2017. 
11. CATTELAN MDP. Avaliação do perfil bioquímico, hematológico, oxidativo e mutagênico e uso de agrotóxicos por trabalhadores rurais do município de Santiago, RS. 2017. Dissertação (Mestrado em Ciências Farmacêuticas). Universidade Federal do Pampa, Campus Uruguaiana, Uruguaiana, RS, 2017. 70f.

12. CORTEZ ACL, et al. Indicadores antropométricos do estado nutricional em idosos: uma revisão sistemática. Journal of Health Sciences, 2015; 14(4): 271-277.

13. CUPARRI L. Nutrição: Nutrição clínica no adulto. 2 ed. Barueri, São Paulo: Manole. 2005.

14. DE MEDEIROS BT, et al. O círculo vicioso da pobreza no Brasil: uma análise da estratégia do programa bolsa família nos municípios do Corede do Vale do Rio Pardo. Revista Grifos, v. 26, n. 42, p. 47-75. 2017.

15. DE OLIVEIRA TF et al. A população idosa de juiz de fora e os gastos com medicamentos: um estudo transversal. Revista Eletrônica Acervo Saúde. 36 (nov. 2019), e2336.

16. DONATTO FF. Nutrição, suplementação e fitoterapia esportiva: ciência e prática. São Paulo: All Print Editora, 2018.

17. FISBERG RM, et al. Métodos de inquéritos alimentares. Inquéritos alimentares: métodos e bases científicos, 2005.

18. GLANER MF. Índice de masa corporal como indicativo de la gordura corporal comparado a los pliegues cutáneos. Revista Brasileira de Medicina do Esporte, 2005; 11(4): 243-246.

19. LOBO V, et al. Free radicals, antioxidants and functional foods: Impact on human health. Pharmacogn Rev, 2010; 4(8): 118-26.

20. MARCON F, et al. Diet-related telomere shortening and chromosome stability. Mutagenesis, v. 27, n. 1, p. $49-57$. 2011.

21. MARTIN FG, et al. Correlação entre estado nutricional e força de preensão palmar em idosos. Rev Bras Geriatr Gerontol. v.15, n.3, p.493-504. 2012.

22. MENEGAT RP e FONTANA RT. Condições de trabalho do trabalhador rural e sua interface com o risco de adoecimento. Cienc Cuid Saúde, 2010; 9(1):52-9.

23. NASCIMENTO KAO, et al. Frequência cardíaca para estimativas da carga física de trabalho na exploração florestal. biofix Scientific Journal, v.1, n.1, p. 210-215, 2018.

24. Organizaçâo Internacional Do TRABALHO (OIT). Cartilha sobre o trabalho florestal - 2009.

25. Organização Mundial da Saúde (OMS). Global Status Report on Noncommunicable Diseases. Genebra, 2010.

26. Organização Mundial da Saúde (OMS). Global Status Report on Noncommunicable Diseases. Genebra, 2010.

27. SCHEURIG AC, et al. Association between the intake of vitamins and trace elements from supplements and $\mathrm{C}$-reactive protein: results of the MONICA/KORA Augsburg study. Eur J Clin Nutr., 2008; 62(1): 127-37.

28. SHELTON RC e MILLER AH. Eating ourselves to death (and despair): the contribution of adiposity and inflammation to depression. Progress in neurobiology, 2010; 91(4): 275:299.

29. SOARES LR, et al. A transição da desnutrição para a obesidade. Braz J Surg Clin Res, v. 5, n. 1. 2014. SOUZA TT. Excesso de peso e obesidade abdominal em trabalhadores terceirizados do setor de reflorestamento: prevalência e fatores associados. 2014.

30. VASCONCELOS FAG. Avaliação Nutricional de Coletividades. 4 ed. Florianópolis: UFESC, 2007.

31. ZANDONADI RP, et al. Atitudes de risco do consumidor em restaurantes de auto - serviço. Revista de Nutrição, Campinas, 2007; 20(1): 19-26. 